\title{
LA COLECCIÓN DE PINTURAS DE PEDRO DE GUZMÁN, I CONDE DE OLIVARES
}

\section{PEDRO DE GUZMÁN, $1^{\text {ST }}$ COUNT OF OLIVARES'S PAINTING COLLECTION}

\author{
José Manuel Ortega Jiménez \\ Universidad de Alcalá. España \\ ORCID: 0000-0001-7620-4200 \\ joseoj13@gmail.com
}

\begin{abstract}
En este artículo se pretende analizar la colección de pinturas que poseyó don Pedro de Guzmán, I conde de Olivares, tasada en 1569 y ubicada en el palacio de su villa homónima en el Aljarafe sevillano. Del mismo modo, se apuntan los nombres de varios artistas que pudieron realizar algunos de los lienzos de este interesante conjunto en el que se contabiliza un centenar de pinturas de distintos géneros -retratos, mitología, religión, costumbrista e historia-. Su importancia reside en que nos encontramos ante la primera referencia de las pinturas que poseyó el linaje, una colección acorde a los gustos de la nobleza de la época que sería heredada por su hijo Enrique de Guzmán.

Palabras clave: palacio de Olivares; I conde de Olivares; Pedro de Guzmán; pinturas; colección.
\end{abstract}

This paper examines the collection of paintings owned by don Pedro de Guzmán, $1^{\text {st }}$ Count of Olivares, appraised in 1569. It was placed in his palace in Olivares, village belonging to the Aljarafe (Seville). On the other hand, several artists' names who may have created some of the canvases of this interesting architectural ensemble will be mentioned. These paintings deal with different subjects: portraits, mythology, religion, local everyday life and history. The relevance of this collection lies in the fact that it is the first reference of the paintings which owned his lineage, a collection in line with the aristocratic taste of that time. Enrique de Guzmán, heir of don Pedro de Guzmán, will inherit such collection.

Keywords: Olivares's Palace; $1^{\text {st }}$ Count of Olivares; Pedro de Guzmán; paintings; collection.

Pedro de Guzmán, natural de Sevilla, fue el cuarto hijo de Juan Alonso Pérez de Guzmán, III duque de Medina Sidonia, y de Leonor de Guzmán y Zúñiga, hija de Pedro de Zúñiga, duque de Béjar. Pasó su infancia y juventud entre la ciudad hispalense y Sanlúcar de Barrameda (Cádiz), donde fue educado por un ayo 
en las "primeras letras". Debido a su fuerte complexión física, con 19 años, entró a servir al emperador Carlos $\mathrm{V}$ en el ejercicio de las armas, y contribuyó al cese de las revueltas de los comuneros en lugares como Andújar, Linares y Toledo ${ }^{1}$. Comenzó, así, una carrera política y cortesana que se vio impulsada durante el viaje que realizó junto al monarca a Italia, Alemania y Flandes. El 12 de octubre de 1535, Carlos V y la reina Juana le concedieron el título de conde de Olivares en Palermo $^{2}$. Nacía una nueva casa nobiliaria, rama menor de los Medina Sidonia, que participará de forma activa en los acontecimiento más importantes de la Monarquía Hispánica durante las siguientes décadas.

Pedro de Guzmán convierte la villa de Olivares en la cabeza de su mayorazgo y adquiere las poblaciones de Castilleja de la Cuesta, Castilleja de Guzmán y Heliche, sitas en el Aljarafe sevillano ${ }^{3}$. En 1539 contrae nupcias con Francisca de Ribera Niño, hija de Lope de Conchillos, secretario de Fernando el Católico, y María de Ribera Niño. No era el primer matrimonio de Francisca, pues anteriormente había estado casada con don Pedro de Ayala, III conde de Fuensalida. La muerte de este último la convirtió en heredera de sus bienes libres ${ }^{4}$, dinero que emplearía para hacer frente a los 14.000 .000 de maravedíes que entregó a Pedro de Guzmán como dote 5 . De esta unión nacieron nueve hijos: Enrique, primogénito y heredero del mayorazgo, Juan, Félix, Pedro, Teresa, Francisca, María, Leonor y Ana Félix.

Durante los siguientes años, el conde continuó su carrera cortesana. En 1552 fue nombrado alcaide de los Reales Alcázares de Sevilla y dos años después, en 1554, contador mayor. Estos cargos le proporcionaron importantes réditos económicos que invirtió, a su vez, en la compra de nuevas tierras y juros, así como en la adquisición de más de cuarenta casas distribuidas en distintas collaciones de la ciudad de Sevilla, todo ello ligado al estado de Olivares ${ }^{6}$. Hacia 1563 los condes se asientan definitivamente en Madrid, sede de la corte desde 1561. En la ciudad del Manzanares, Pedro de Guzmán otorga testamento ante el escribano Francisco de Henao en 15647. En ella fallece el 16 de agosto de 1569, siendo

${ }^{1}$ Martínez Calderón, 1638: 566-569. Se trata de una obra manuscrita que se localiza en la Biblioteca Nacional de España (BNE), mss. 2258.

2 "Tenemos por bien y es $\mathrm{n}[\mathrm{ues}] \mathrm{t}[\mathrm{r}] \mathrm{a}$ m[e]r[ce]d y voluntad $\mathrm{q}[\mathrm{u}] \mathrm{e}$ agora y de aqui adelante para siempre jamas os podays llamar e intitular y os llameys e intituleys y nos por la presente os llamamos e intitulamos conde de villa de olivares $\mathrm{q}[\mathrm{u}] \mathrm{e}$ dezis q[ue] es ora cerca de sevilla". Archivo Ducal de la Casa de Alba (ADA), C. 295, nº 5.

${ }^{3}$ Herrera García, 1990: 47.

${ }^{4}$ Franco Silva, 1994: 106.

5 Archivo Histórico de Protocolos de Madrid (AHPM), prot. 436, escribano Cristóbal de Peñalver, f. 330r.

${ }^{6}$ La escritura definitiva de la fundación del mayorazgo se llevó a cabo en 1563 y se localiza en el AHPM, prot. 436, escribano Cristóbal de Peñalver, ff. 319r-342v.

${ }^{7}$ Herrera García, 1990: 68. 
enterrado en la parroquia de Santa María de la Almudena de Madrid hasta que, años después, sus restos son trasladados a la iglesia de Santa María de las Nieves en Olivares donde se encuentran en la actualidad ${ }^{8}$.

El 10 de octubre de 1569, unos meses después de la muerte del conde, se llevó a cabo el registro de sus bienes en Sevilla ante el escribano hispalense Diego de Portes 9 . Junto a los distintos lotes de juros, se inventariaron numerosos bienes muebles. Aunque en el documento no se señala, es probable que se esté refiriendo a los bienes que se localizaban en el palacio de Olivares, un suntuoso inmueble cuya construcción había comenzado en 1535 (Figura 1).

El edificio ha llegado a nuestros días con intervenciones sustanciales que han variado su estructura original. A pesar de ello, aún se conseva una de las tres portadas y uno de los escudos del linaje que se encargaron al artista italiano Solari da Carona en $1536^{10}$. Destaca el patio principal, un bello claustro cuadrangular de dos alturas. En su planta baja se distribuyen sendas galerías de arcos de medio punto peraltados apoyados en columnas de mármol genovés con capiteles de moñas (Figura 2). El palacio de Olivares sigue, por tanto, las tendencias clasicistas que llegaron a la ciudad del Guadalquivir a partir de 1530 de la mano del primer marqués de Tarifa, y cuyos ejemplos principales eran la casa Pilatos y el palacio de las Dueñas ${ }^{11}$.

Una vez concluidas las obras del inmueble, Pedro de Guzmán se preocupó por acondicionar su interior con el fin de convertirlo en el símbolo de la familia. En el inventario post mortem de 1569, se recoge un respetable ajuar formado por pinturas, muebles, tapices, piezas de decoración, vajilla para el servicio de mesa y objetos del servicio de calefacción y cocina. Asimismo, se contabilizan "quatro piezas labradas de piedra negra que pareçen p[ar]a portada de chiminea", posiblemente una remesa de piezas italianas. Nos encontramos ante un conjunto privado, sin carácter expositivo y alejado del concepto de las cámaras de las maravillas (wunderkammer). No obstante, observamos varios objetos a tono con el gusto de la época como varios relojes, una escultura de un niño con un perrito y

${ }^{8}$ En 1574 Francisca de Ribera fue enterrada junto a su marido en la parroquia de Santa María de la Almudena. "En 29 de julio de 1574 años se enterro la Illu[strísi]ma s[eño]ra condesa de olivares dio del Rompimiento seiscientos reales mas dio sesenta reales de cierta madera que la yglesia le dio para su tumulo dio mas tres ducados de una tumba que le dio la yglesia”. Archivo de la parroquia de Santa María la Real de la Almudena de Madrid (APSMRA), libro I de difuntos, f. 30r.

9 Archivo Histórico Provincial de Sevilla (AHPSe), protocolos, legajo 10672, oficio 17 , libro $2^{\circ}, 1569$, ff. 463 r-473r. A este documento se referirán todos los datos del inventario de 1569 mientras no se indique otra referencia.

${ }^{10}$ Sobre la construcción del palacio véase Alizeri, 1877: 116-118. Marín Fidalgo, 1990: 127-136.

${ }^{11}$ Lleó Cañal, 1979: 33. Falcón Márquez, 2003: 20. 
dos "espejos grandes de azero guarnesçidos de evano con sus corredizas de tafetan e sus puertas"12.

Por el contrario, percibimos un destacado interés por la pintura, cuya presencia se acentúa en los inventarios artísticos de la segunda mitad del siglo XVI ${ }^{13}$. Se enumeran un centenar de ejemplares en tabla y en lienzo que se distribuirían por las distintas estancias del palacio. Su importancia radica en que se trata de la primera referencia documental de la colección pictórica de los condes de Olivares. Aunque es difícil precisar la fecha en la que Pedro de Guzmán comenzó a reunir este conjunto, creemos que pudo ser a partir de su nombramiento como conde de Olivares en 1535.

En las últimas décadas las investigaciones sobre coleccionismo de pinturas han dado lugar a importantes trabajos. En 1985, Morán Turina y Checa Cremades publicaron El coleccionismo en España ${ }^{14}$. Tomando como referencia el estudio que Julius von Schlosser realizó a comienzos del siglo $\mathrm{XX}^{15}$, efectuaron una primera aproximación a los inventarios reales y de la nobleza desde la época medieval hasta el reinado de Felipe IV.

En lo que concierne al ámbito andaluz, y más concretamente al sevillano, destacamos las Curiosidades antiguas sevillanas de José Gestoso y Pérez, quien trata diversos aspectos de la sociedad hispalense entre los siglos XIV y XVII y da a conocer algunos datos referentes a la colección de pinturas de los marqueses de Tarifa en la Casa de Pilatos ${ }^{16}$. Del mismo modo, debemos señalar el artículo de Sanz Serrano y Dabrio González sobre los inventarios sevillanos de comienzos del siglo XVIII ${ }^{17}$. Por último, apuntamos el estudio de Urquízar Herrera donde se ofrece un pormenorizado análisis de los bienes y el modo de vida de la nobleza andaluza del siglo $\mathrm{XVI}^{18}$.

Pese a la importante producción científica sobre el tema, nada se ha dicho de la colección pictórica del I conde de Olivares ${ }^{19}$. Por este motivo, creemos necesario dar a conocer este conjunto que, como ya se ha indicado, estaba formado por un centenar de pinturas en lienzo y tabla. Ignoramos si por su propia afición y gusto personal o como mero instrumento para ennoblecer y realzar al nuevo linaje, lo cierto es que don Pedro siguió el ejemplo de otras familias importantes de

${ }_{12}$ AHPSe, protocolos, legajo 10672, oficio 17, libro $2^{\circ}$, 1569, ff. 468r-470r.

${ }_{3}^{3}$ Morán/Checa Cremades, 1985: 153.

${ }_{14}$ Morán/Checa Cremades, 1985.

15 Von Schlosser, 1988.

${ }^{16}$ Gestoso y Pérez, 1910.

17 Sanz Serrano/Dabrio González, 1974: 89-150.

18 Urquízar Herrera, 2007.

19 Herrera García, 1990: 63, dio a conocer el inventario, aunque lo analizó desde un punto de vista económico. Un primer estudio sobre el patrimonio mueble e inmueble del I conde de Olivares en Ortega Jiménez, 2019. 
la época como los duques del Infantado o los Medina Sidonia y destinó parte de su hacienda a la adquisición de obras pictóricas ${ }^{20}$.

Hasta el momento no se ha logrado localizar ninguna de las pinturas puesto que en el inventario no se hace referencia a su procedencia ni a los artífices. No obstante, dado que el registro se llevó a cabo en Sevilla, pensamos que una parte de estas obras fue ejecutada por artistas de origen sevillano o establecidos en la ciudad hispalense. Entre los maestros más destacados encontramos a Pedro de Campaña (1500/1503-1580), Hernando de Esturmio (1510/1515-1556) y Vasco Pereira (1535-1609), vinculados a la clientela eclesiástica y nobiliaria de la época ${ }^{21}$. De hecho, todos ellos trabajaron en distintos momentos para los Medina Sidonia $^{22}$. No descartamos la posibilidad de que Pedro de Guzmán pidiera consejo a sus parientes para iniciar su colección de pinturas y, por tanto, entre sus cuadros se encontraran obras de estos artistas.

En el caso particular de Vasco Pereira, creemos que el contacto entre el pintor y el linaje de los Olivares continuaría en los años siguientes. En 1600, tres décadas después de la muerte del I conde de Olivares, su heredero Enrique de Guzmán donó al convento de Santiponce (Sevilla) una reliquia de San Eutiquio, adquirida en Roma durante los años que fue embajador ante la Santa Sede. Con ocasión de la llegada de esta pieza, se encargó una pintura del santo titular que aún se conserva en la iglesia y que se atribuye al citado $\operatorname{pintor}^{23}$. Aunque no hemos encontrado referencias documentales, creemos que pudo ser un encargo personal del II conde de Olivares (Figura 3). Por tanto, y si nuestra hipótesis es correcta, el contacto entre los Olivares y Pereira se habría iniciado con el I conde y prolongado en tiempos de su heredero.

Retomando el estudio de la colección de pinturas de Pedro de Guzmán, la trayectoria política del I conde le permitió acompañar a Carlos $\mathrm{V}$ y al príncipe Felipe a Italia, Alemania o Bruselas. Esto nos lleva a plantear la posibilidad de que algunos de estos lienzos, sobre todo los desnudos, las pinturas mitológicas y las de género, se adquirieran en el extranjero, como veremos a continuación.

Del centenar de cuadros que se inventarían sobresalen los retratos, un total de veintiocho. Se representan personas anónimas como los ocho lienzos de mujeres - dos de ellas alemanas, una de Parma, una flamenca y otra extranjera-, dos de la turca, dos sin nombre, uno de una niña con un perrito, uno de "un loco con un mochuelo en la mano" y una tabla de dos viejos escribiendo un libro ${ }^{24}$. Estas tres últimas pinturas son escenas cotidianas y muestran cómo el conde de Olivares se

${ }^{20}$ Véase Heredia Moreno, 2012: 241-255.

21 Valdivieso, 1986: 67 y 74. Rojas-Marcos González, 2015: 148 y 151. Ros González, 2015: 563. Sobre Vasco Pereira véase Serrera Contreras, 1987: 197-242.

${ }^{22}$ Cruz Isidoro, 2011: 85; 2002: 356-357.

${ }^{23}$ Respaldiza Lama, 2002: 198.

${ }^{24}$ AHPSe, protocolos, legajo 10672, oficio 17, libro $2^{\circ}$, 1569, ff. 467r-467v. 
interesó por un género que, si bien gozaba de gran éxito en los Países Bajos, no fue usual en los inventarios de los nobles españoles hasta principios del siglo XVII ${ }^{25}$. Sin embargo, hay constancia de que a lo largo de la centuria anterior, llegó a Sevilla un interesante número de pinturas desde Flandes, muchas de ellas destinadas a grandes palacios ${ }^{26}$.

Entre 1548 y 1552, el I conde de Olivares acompañó al príncipe Felipe en su viaje por Europa ${ }^{27}$. Entre otros lugares visitan Italia, Alemania y Flandes. En esta última región visitaron, entre otros lugares, la ciudad de Amberes. En esta localidad se desarrolló una de las escuelas más prolíficas del Renacimiento que tuvo intensas conexiones comerciales con España ${ }^{28}$. Recordemos que, entre otros artistas de renombre, trabajaban en estos momentos Pieter Porbous, Pieter Aertsen, Marcelo Coffermans o Marinus van Reymerswaele, este último importante autor de escenas costumbristas ${ }^{29}$. No sería del todo improbable que Pedro de Guzmán encargara las tres pinturas mencionadas - niña con un perrito, loco con un mochuelo y la tabla de los viejos escribiendo un libro- durante la escala de la comitiva en Amberes (1549). De esta manera incluiría ejemplares acordes con el gusto del futuro monarca que sentía una fuerte afición por la pintura del norte ${ }^{30}$.

Finaliza el apartado de los retratos con uno de la condesa de Ricla y tres de los condes de Olivares - dos de Francisca de Ribera y uno de Pedro de Guzmán- ${ }^{31}$. El objetivo principal sería el de enaltecer el valor e identidad de la familia ${ }^{32}$. No descartamos que estas pinturas formaran parte de una galería de retratos. De igual manera, la presencia de los retratos de Carlos I y Felipe II, que se expondrían junto a las dos tablas grandes de "armas ynperiales doradas", subrayan el vínculo de la monarquía con el nuevo linaje, cuyos éxitos políticos y cortesanos estarán ligados al devenir histórico de la Casa de Austria desde 1535. Por último, esta serie se completaba con tres retratos de Lucrecia, dos de Cleopatra y dos de Petrarca con una "dama laurea", pinturas de personajes históricos con tintes alegóricos $^{33}$. Otras personalidades de la época que poseyeron destacables galerías de retratos fueron Antonio Pérez, secretario de Felipe II y el III marqués de Pozas ${ }^{34}$.

${ }^{25}$ Brown, 1990: 131.

26 Valdivieso, 2009: 233.

27 Calvete de Estrella, 1930.

28 Kloek, 2009: 272.

29 Valdivieso, 1989: 95.

${ }^{30}$ Checa Cremades/Sáenz de Miera, 1994: 226. Cano de Gardoqui García, 2001: 100.

${ }^{31}$ AHPSe, protocolos, legajo 10672, oficio 17, libro $2^{\circ}, 1569$, f. $467 \mathrm{v}$.

32 Urquízar Herrera, 2007: 40. Carrió-Invernizzi, 2014: 114.

33 AHPSe, protocolos, legajo 10672, oficio 17, libro $2^{\circ}, 1569$, ff. 466v-467v.

${ }^{34}$ Morán/Checa Cremades, 1985: 162. 
Fue común entre la nobleza sevillana del siglo XVI poseer un destacable número de pinturas mitológicas y alegóricas ${ }^{35}$. Pedro de Guzmán atesoró un total de veintidós escenas de este género, un número superior al que se registró en el inventario post mortem de su primo Alonso Pérez de Guzmán, VII duque de Medina Sidonia, en $1588^{36}$. El conde de Olivares no fue ajeno al sentir de la época y mostró un destacado interés por las corrientes humanistas y clásicas que se extendían desde Italia a la ciudad del Guadalquivir ${ }^{37}$.

A los siete lienzos de las Virtudes, se añade una "tabla grande" de la Caridad. La diosa Venus aparece representada en cuatro pinturas - dos sola, una con su hijo Cupido y una con Adonis y unos perros-. Se recoge, además, una del dios Júpiter convertido en toro, una de un niño con un sátiro, una de la diosa Artemisa con "una cosa en la mano", probablemente las flechas, una mediana del dios Baco y una de Perseo con Andrómeda. Dentro de este conjunto debemos incluir tres lienzos y una tabla de desnudos femeninos, destacando el "de una muger desnuda bistiendose una camisa" y otro "con bastidor dorado de una mujer desnuda en la cama" 38 .

Dado su carácter pagano, las pinturas de desnudo no solían ejecutarse en la península Ibérica, por lo que nos aventuramos a pensar que Pedro de Guzmán adquirió estos ejemplares durante el viaje que realizó a Italia con el príncipe Felipe $^{39}$. Aunque no hemos hallado referencias documentales, apuntamos la posibilidad de que las encargara personalmente a artistas de prestigio como Tiziano, a quien pudo conocer a finales de 1548 o principios de 1549 en Milán, con ocasión del encuentro entre el artista veneciano y el heredero al trono español ${ }^{40}$. La representación de la mujer desnuda y recostada sobre una cama responde a un modelo que tuvo una importante acogida dentro de la escuela veneciana de comienzos del siglo XVI. El pintor veneciano contribuyó a su desarrollo y éxito posterior. Entre sus obras destacamos la Venus de Urbino, encargada por Girolamo II en 1538, y considerada una de las más importantes de su carrera ${ }^{41}$.

La pérdida de estas obras nos impide llegar a una conclusión sobre la autoría. En todo caso, su posesión nos habla del carácter novedoso del conjunto pictórico del conde de Olivares, pues los desnudos no fueron abundantes entre las colecciones de los nobles españoles.

${ }^{35}$ Lleó Cañal, 1979: 58.

${ }^{36}$ En total se contabilizaron diez y nueve escenas mitológicas y alegóricas. Cruz Isidoro, 2003: 155.

37 Valdivieso, 1988: 53.

${ }_{38}$ AHPSe, protocolos, legajo 10672, oficio 17, libro $2^{\circ}, 1569$, ff. 466r-467v

39 Angulo Íñiguez, 2009: 31-32.

40 Mancini, 2009: 250.

${ }^{41}$ Checa Cremades, 2005: 83; 2013: 155 y 157. 
El tercer lugar, con un número de diez y nueve, es para las escenas religiosas. La mayoría de ellas representan sucesos recogidos en el Nuevo Testamento como una de la matanza de los Inocentes, una del hijo pródigo, una del rico avariento y dos de Herodías, una con "la cabeza de san ju[an]". Se citan, además, cuatro pinturas de Cristo - dos pequeñas con San Juan Bautista representados como niños, una bajando al Limbo y una grande del "sepulcro"-. Algo menos numerosos son los episodios referidos al Antiguo Testamento. Contabilizamos dos tablas de Judit, una de Susana y una de Abraham. Se completa este apartado con dos cuadros de santos, uno "grande viejo de la conversion de san pablo" y otro de San Jerónimo, dos de María Magdalena, uno de ellos descrito como una tabla "grande de las tentaçiones", uno del Purgatorio y, para terminar, uno de Nuestra Señora ${ }^{42}$.

Menor representación tienen los lienzos de paisajes, inventariándose ocho que se definen como "viejos". Dado que este tipo de pinturas es más propio de colecciones de finales del siglo XVI y principios del XVII ${ }^{43}$, creemos que puede estar haciendo referencia a vistas de ciudades. A través de un documento publicado por Cruz Isidoro, sabemos que en 1567 Pedro de Guzmán actuó como intermediario entre el pintor Antón van den Wyngaerde y su pariente el VII duque de Medina Sidonia. Este último pagó al artista 50 ducados en reales para que realizara las vistas de algunas ciudades gaditanas ${ }^{44}$. Con ello contribuía al interés de Felipe II de realizar una relación topográfica de las urbes más importantes de España.

La relación entre Wyngaerde, vecino de Madrid desde 1562, y el conde de Olivares se debe remontar a 1563, año en el que pensamos que los nobles se instalaron definitivamente en la corte. A partir de este momento, los condes firman en la villa del Manzanares la mayor parte de documentos legales como la escritura definitiva de fundación del mayorazgo (1563) o el testamento de Pedro de Guzmán $(1564)^{45}$. Pedro de Guzmán pudo encargar estos lienzos al artista amberino y enviarlos, tiempo después, al palacio de Olivares. Junto a los paisajes, se mencionan dos "papelones de una carta marina y la guerra de alemania Viejos"46. La posesión de mapas y cartas marinas en las colecciones son muestra de una mayor cultura geográfica entre la clase aristocrática. Pero además, estos ejemplares ofrecían información de un terreno concreto. En un periodo conflictivo como el siglo XVI eran una valiosa herramienta en caso de intervenciones militares o de gobierno ${ }^{47}$. Un ejemplo que ilustra muy bien este cambio de mentalidad es la tasación post mortem del VI duque de Medina Sidonia (1558) donde se registró un lienzo con

\footnotetext{
${ }^{42}$ AHPSe, protocolos, legajo 10672, oficio 17, libro $2^{\circ}$, 1569, ff. 467r-467v.

43 Morán/Checa Cremades, 1985: 241.

${ }^{44}$ Cruz Isidoro, 2014: 164.

${ }^{45}$ Herrera García, 1990: 68.

46 AHPSe, protocolos, legajo 10672 , oficio 17 , libro $2^{\circ}, 1569$, f. $467 \mathrm{v}$.

47 Hernando, 2007: 16. Morte García, 2017: 67.
} 
la guerra de Inglaterra, uno con la guerra de Nápoles, uno de la ciudad de Argel, uno de la ciudad de África y un mapamundi ${ }^{48}$.

De igual manera se registran siete pinturas de "historias" de las que no se especifica el contenido y varias sin título, una de ellas quebrada. Tampoco se describen los siete "lienços de los planetas". Desde nuestro punto de vista, se trataría de la representación alegórica de los planetas, personificados como dioses romanos ${ }^{49}$.

Para esta serie se pudieron tomar como modelo las esculturas realizadas por Jacques Jonghelinck para el duque de Aumale entre 1563 y $1567^{50}$. En cuanto a su autoría, barajamos el nombre de Frans Floris, un pintor de Amberes que, en torno a 1560, realiza unos lienzos del mismo tema para Martín de Gurrea y Aragón, duque de Villahermosa, con destino a su palacio de Pedrola (Zaragoza) ${ }^{51}$. Esta hipótesis quedaría reforzada si tenemos en cuenta que la relación entre Villahermosa y el conde de Olivares debió de ser fluida. Sabemos que ambos formaron parte de la comitiva que acompañó al príncipe Felipe a Londres en 1554 con ocasión de su matrimonio con María de Inglaterra ${ }^{52}$. Del mismo modo, planteamos la posibilidad de que en 1549 Pedro de Guzmán encomendara personalmente las obras durante su estancia en Amberes, ciudad en la que Flans Floris tenía un importante taller ${ }^{53}$. La confirmación de esta autoría nos permitiría añadir nuevas obras al catálogo de un artista cuya presencia en la Sevilla del siglo XVI fue notable ${ }^{54}$.

En síntesis, y basándonos en lo dicho hasta este momento, nos encontraríamos ante una interesante colección formada por un centenar de pinturas en tabla y en lienzo de distintos géneros -retratos, mitología, religión, costumbrista y escenas históricas-. Dicho conjunto estaría representado por ejemplares de la escuela española, italiana y flamenca. Del mismo modo, pensamos que algunos de estos cuadros pudieron ser realizados por afamados pintores del momento tales como Pedro de Campaña, Hernando de Esturmio, Vasco Pereira, Frans Floris o Tiziano. En definitiva, bien como signo de identidad social del linaje, bien como afición e interés personal, lo cierto es que el I conde de Olivares, Pedro de Guzmán, siguió una política coleccionista similar a la de otros nobles contemporáneos y se interesó por el ambiente cultural de la época.

Tras la muerte del I conde de Olivares en 1569, esta colección de pinturas pasó a poder de su hijo y heredero. Enrique de Guzmán, sirviéndose de su buena

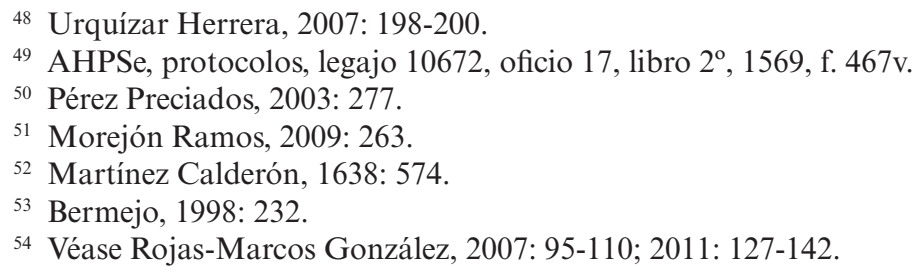


situación económica y de su cargo como embajador de Roma y virrey de Sicilia y Nápoles, amplió dicha colección con una treintena de lienzos, entre los que se encuentran obras de Scipione Pulzone y Pasquale Cati, algunas de ellas destinadas a la futura iglesia de Santa María de las Nieves en Olivares, su fundación más ambiciosa.

Fecha de recepción: 24 de julio de 2019

Fecha de aceptación: 13 de abril de 2020

\section{BIBLIOGRAFÍA}

Alizeri, Federigo (1877): Notizie dei professori del disegno in Liguria dalle origini al secolo XVI. Génova: Tipografia di Luigi Sambolino, vol. V.

Angulo Íñiguez, Diego ([1952] 2009): "La Mitología y el Arte Español del Renacimiento". En: Pita Andrade, José Manuel (coord.): La mitología en el arte español: del Renacimiento a Velázquez. Madrid: Real Academia de la Historia.

Bermejo, Elisa (1988): "Lucas Cranach, el Viejo y Frans Florís: pinturas firmadas, en colecciones españolas". En: Archivo Español de Arte, 283, pp. 223-240.

Brown, Jonathan (1990): La Edad de Oro de la pintura en España. Madrid: Nerea.

Calvete de Estrella, Juan Cristóbal ([1552] 1930): El felicissimo viaje del muy alto y muy Poderoso Principe Don Phelippe Hijo d'el Emperador Don Carlos V [...]. Madrid.

Cano de Gardoqui García, José Luis (2001): Tesoros y colecciones. Orígenes y evolución del coleccionismo artístico. Valladolid: Universidad de Valladolid.

Carrió-Invernizzi, Diana (2014): "La galería de retratos de virreyes de la Monarquía Hispánica, entre Italia y América (siglos XVI-XVII)". En: Aznar, Daniel/ Hanotin, Guillaume/May, Niels. F. (dirs.): À la place du roi vicerois, gouverneurs et ambassadeurs dans les monarchies française et espagnole (XVIe-XVIIIe siècles). Madrid: Casa de Velázquez, pp. 113-134.

Checa Cremades, Fernando (2005): “Tiziano, Venus, la Música y la idea de la Pintura". En: Quintana, 4, pp. 83-97.

(2013): Tiziano y las cortes del Renacimiento. Madrid: Marcial Pons.

Checa Cremades, Fernando/Sáenz de Miera, Jesús (1994): "La corte española y la pintura de Flandes". En: Checa Cremades (dir.): El real alcázar de Madrid. Dos siglos de arquitectura y coleccionismo en la corte de los reyes de España. Madrid: Nerea, pp. 220-235.

Cruz Isidoro, Fernando (2002): "Vasco Pereira y la serie de seis retablos dominicos para la Casa Ducal de Medina Sidonia". En: Laboratorio de Arte, 15, pp. 357-364.

- (2003): "La colección pictórica del palacio sanluqueño de la casa ducal de Medina Sidonia entre los años de 1588 y 1764”. En: Laboratorio de Arte, 16, pp. 151-169. 
- (2011): "El convento de Santo Domingo de Sanlúcar de Barrameda: patronazgo de los Guzmanes, proceso constructivo y patrimonio artístico". En: Laboratorio de Arte, 23, pp. 79-106.

(2014): “Antonio de las Viñas y los Pérez de Guzmán. Sobre la «ejecución y pintura de ciertos lugares de España» en 1567: ¿las vistas de Tarifa, Zahara de los Atunes y Sanlúcar de Barrameda?". En: Archivo Español de Arte, 346, pp. 163-170.

Falcón Márquez, Teodoro (2003): El palacio de las Dueñas y las casas-palacios sevillanas del siglo XVI. Sevilla: Fundación Cultural del Colegio Oficial de Aparejadores y Arquitectos Técnicos.

Franco Silva, Alfonso (1994): El condado de Fuensalida en la Baja Edad Media. Cádiz: Universidad de Cádiz.

Gestoso y Pérez, José (1910): Curiosidades antiguas sevillanas. Sevilla: El Correo de Andalucía.

Hernando, Agustín (2007): Coleccionismo cartográfico en el siglo XVII. Ejemplares reunidos por Vicencio Juan de Lastanosa (1607-1681) y su significado. Huesca: Instituto de Estudios Altoaragoneses.

Heredia Moreno, Carmen (2012): "El patrimonio suntuario de los V duques del Infantado". En: Rivas Carmona, Jesús (coord.): Estudios de platería. Murcia: Universidad de Murcia, pp. 241-255.

Herrera García, Antonio (1990): El estado de Olivares. Origen, formación y desarrollo con los tres primeros condes (1535-1645). Sevilla: Diputación Provincial de Sevilla.

Kloek, Wouter (2009): "Pieter Aertsen, el artista y su impacto". En: AA.VV.: La senda española de los artistas flamencos. Madrid: Galaxia Gutenberg, pp. 265-285.

Lleó Cañal, Vicente (1979): Nueva Roma: mitología y humanismo en el Renacimiento sevillano. Sevilla: Diputación Provincial de Sevilla.

Mancini, Matteo (2009): Ut pictura poesia: Tiziano y su recepción en España. Tesis doctoral. Madrid: Universidad Complutense de Madrid.

Marín Fidalgo, Ana María (1990): "Mármoles procedentes de los talleres de Génova para el palacio de Pedro de Guzmán en Olivares (Sevilla)". En: Archivo Hispalense, 224, pp. 127-136.

Martínez Calderón, Juan Alfonso (1638): Epítome de las historias de la gran casa de Guzmán y de las progenies reales que la procrean y las que procrea, donde se da noticia de esta antigua familia y de otras muchas de Europa. Madrid, vol. III.

Morán, Miguel/Checa Cremades, Fernando (1985): El coleccionismo en España. De las cámaras de maravillas a la galería de pinturas. Madrid: Cátedra.

Morejón Ramos, José Alipio (2009): Nobleza y humanismo. Martín de Gurrea y Aragón. La figura cultural del IV duque de Villahermosa (1526-1581). Zaragoza: Instituto Fernando el Católico. 
Morte García, Carmen (2017): "El patrocinio artístico de las clases privilegiadas: prestigio y devoción durante el Renacimiento en Aragón”. En: Ibánez Fernández, Javier (coord. y ed.): Del mecenazgo a las nuevas formas de promoción artística. Actas del XIV Coloquio de Arte Aragonés. Zaragoza: Universidad de Zaragoza, pp. 45-101.

Ortega Jiménez, José Manuel (2019): Linaje, patrimonio y patronazgo artístico de D. Gaspar de Guzmán, Conde Duque de Olivares. Tesis doctoral. Alcalá de Henares: Universidad de Alcalá.

Pérez Preciados, Juan José (2003): "La burocracia española en los Países Bajos y la importación de pintura flamenca: el secretario Miguel de Olivares”. En: Colomer, José Luis (dir.): Arte y Diplomacia de la Monarquía Hispánica en el siglo XVII. Madrid: Centro de Estudios Europa Hispánica.

Respaldiza Lama, Pedro José (2002): "Catálogo". En: AA.VV.: San Isidoro del Campo (1301-2002). Fortaleza de la espiritualidad y santuario del poder. Sevilla: Junta de Andalucía/Consejería de Cultura.

Rojas-Marcos González, Jesús (2007): "La inexistencia del pintor Francisco Frutet”. En: Laboratorio de Arte, 20, pp. 95-110.

(2011): "Nueva obra del círculo de Frans Floris en una colección particular sevillana”. En: Temas de estética y arte, 25, pp. 127-142.

(2015): "La pintura sevillana del Renacimiento". En: Temas de estética y Arte, 29, pp. 139-161.

Ros González, Francisco Sabas (2015): “Trabajos inéditos de Gaspar de Aguilar y Vasco Pereira: el retablo y la imagen de San Roque en la parroquia de San Sebastián de Sevilla". En: Laboratorio de Arte, 27, pp. 559-564.

Sanz Serrano, María Jesús/Dabrio González, María Teresa (1974): "Inventarios artísticos sevillanos del siglo XVIII. Relación de obras artísticas”. En: Archivo Hispalense, 176, pp. 89-150.

Serrera Contreras, Juan Miguel (1987): "Vasco Pereira: un pintor portugués en la Sevilla del último tercio del siglo XVI". En: Archivo Hispalense, 213, pp. 197-242.

Urquízar Herrera, Antonio (2007): Coleccionismo y nobleza. Signos de distinción social en la Andalucía del Renacimiento. Madrid: Marcial Pons.

Valdivieso, Enrique (1986): Historia de la pintura sevillana, siglos XIII al XX. Sevilla: Guadalquivir.

(1988): "La pintura sevillana desde el siglo XVI". En: Cuenta y Razón, 40, pp. 53-60.

(2009): "Pintura flamenca de los siglos XVI y XVII en Sevilla". En: AA.VV.: La senda española de los artistas flamencos. Madrid: Galaxia Gutenberg, pp. 233-247.

Von Schlosser, Julius ([1978] 1988): Las cámaras artísticas y maravillosas del renacimiento tardío. Madrid: Akal. 


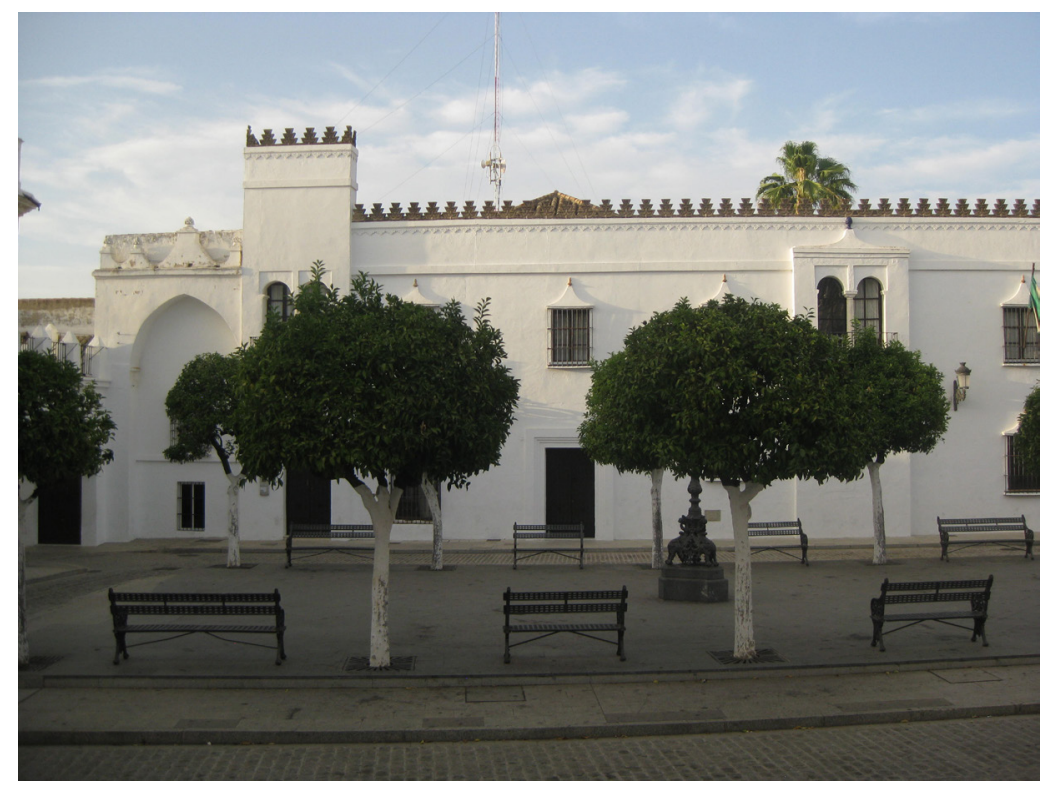

Figura 1. Palacio de Olivares, Olivares (Sevilla).

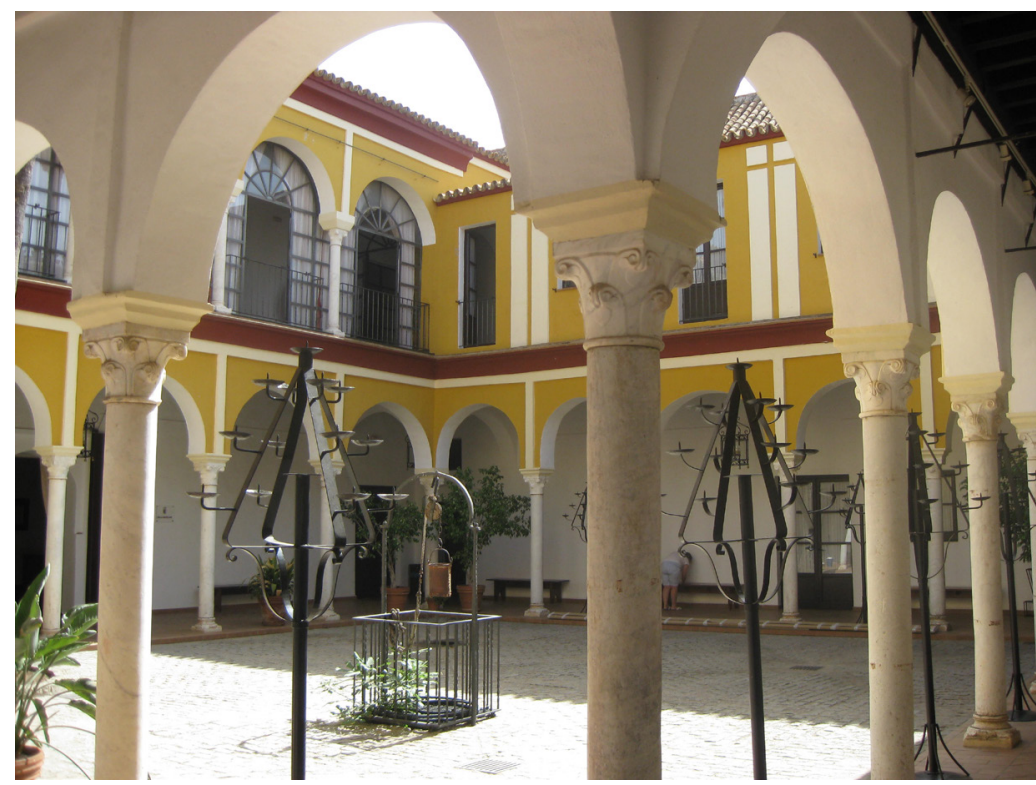

Figura 2. Claustro central del palacio de Olivares, Olivares (Sevilla). 


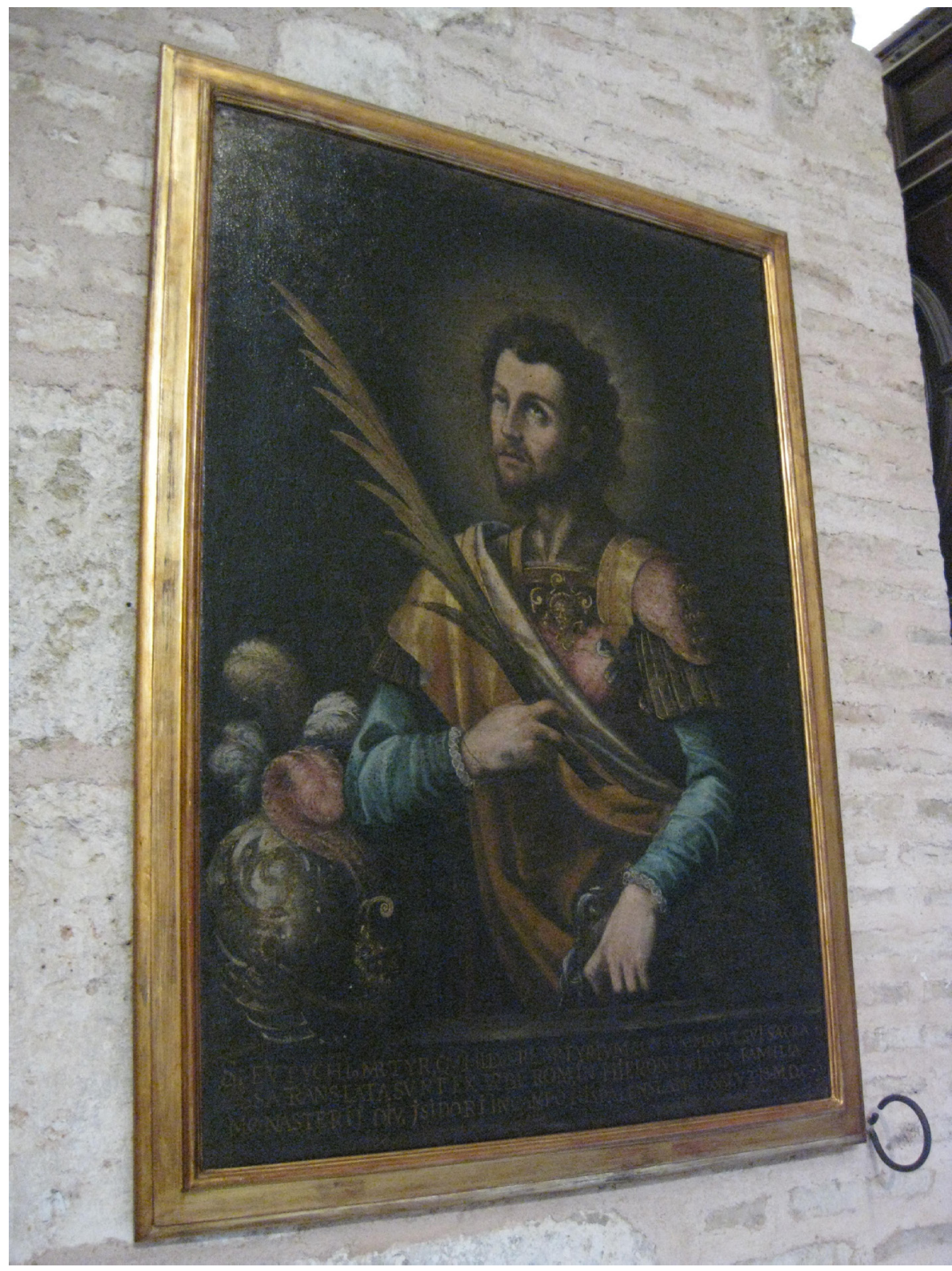

Figura 3. Vasco Pereira (atribución), San Eutiquio, 1600, monasterio de San Isidoro del Campo, Santiponce (Sevilla). 